\title{
Os três porquinhos e o lobo mal:
}

\section{literatura infantil e o ensino de combinatória}

The three little pigs and the bad wolf:

\author{
children's literature and combinatorial teaching
}

Los tres cerditos y el lobo mal:

literatura infantil y la enseñanza de combinatoria

\author{
Adryanne Barreto de Assis \\ Universidade Federal de Pernambuco (UFPE), Recife/PE - Brasil \\ Cristiane Azevêdo dos Santos Pessoa \\ Universidade Federal de Pernambuco (UFPE), Recife/PE - Brasil
}

\section{Resumo}

O presente artigo é fruto da análise da relação entre literatura infantil e matemática, especificamente com o conteúdo da combinatória. Trata-se de um estudo realizado em parceria com a professora da turma, que participou de um processo de formação continuada sobre combinatória, com 06 encontros, durante o qual realizou duas aulas sobre a temática, uma delas relacionando os dois campos de conhecimento. Verificou-se que, durante e após o processo de formação, a professora ressignificou seus conhecimentos, produzindo uma prática contextualizada e com uma alternativa metodológica atualizada. Dessa forma, o estudo indicou que o trabalho com a Literatura Infantil no processo de ensino e aprendizagem da combinatória pode tornar o conteúdo mais significativo.

Palavras-chave: Matemática, Formação continuada, Combinatória, Literatura infantil

\section{Abstract}

This article present the result of the analysis of the relation between Children's Literature and Mathematics, specifically focusing on Combinatorics. The researched teacher took part in a process of continuous education on Combinatorics consisted of 06 meetings and, during the process it was carried out two classes on the subject, one of which related these two fields of knowledge: Children's Literature and Mathematics. It was verified that during and after the training process the teacher resignificated her knowledge, generating a contextualized practice and with an actual methodological alternative. In this way, we verified that working with Children's Literature in the teaching and learning process of Combinatorics can make it more meaningful.

Keywords: Mathematics, Continuing education, Combinatorics, Children's literature

\section{Resumen}

Este artículo presenta la análisis de la relación entre la Literatura Infantil y la Matemática, específicamente con el contenido de la Combinatoria. Se trata de una investigación hecha en conjunto con la maestra, que participó de un proceso de formación continuada sobre Combinatoria, con 06 encuentros en el cual realizó dos 
clases sobre la temática, siendo una relacionando los dos campos de conocimiento. Se verificó que durante y después del proceso de formación la profesora resignificó sus conocimientos, produciendo una práctica contextualizada y con una alternativa metodológica actual. Así qué reconocemos que el trabajo con la Literatura Infantil en el proceso de enseñanza y aprendizaje de la Combinatoria puede volver el contenido más significativo.

Palabras clave: Matemáticas, Formación continua, Combinatoria, Literatura infantil

\section{Introdução}

Os Parâmetros Curriculares Nacionais de Matemática - PCN (BRASIL, 1997) dos anos iniciais do Ensino Fundamental reconhecem a importância de se trabalhar com uma ampla diversidade de conteúdo, incluindo-se, já nos anos iniciais, elementos de estatística, probabilidade e combinatória, para atender à demanda social que indica a necessidade de abordar esses assuntos. Os PCN de Matemática (BRASIL, 1997) também indicam a necessidade dos alunos aprenderem os diferentes tipos de problemas que a combinatória aborda, entre os quais, arranjos, combinações, permutações e, especialmente, o princípio multiplicativo da contagem.

Contudo, a combinatória não é, de um modo geral, trabalhada na formação de professores, especificamente nos cursos de pedagogia. De acordo com Silva (2015), os livros didáticos destinados ao ensino médio contemplam a maior concentração de problemas que envolvem o raciocínio combinatório, o que faz com que haja uma maior exploração deste conteúdo nos cursos de formação de professores destinados a este nível de ensino.

São poucas as escolhas metodológicas apresentadas aos futuros professores dos anos iniciais para o trabalho com esse conteúdo específico, e, com isso, eles nem sempre conseguem criar condições facilitadoras e desenvolver um processo que garanta a aprendizagem desse conhecimento. Isso faz com que, na maioria das vezes, o professor deixe de abordar o tema na sala de aula.

Uma das alternativas de ensino pensadas para assegurar uma maior e melhor efetividade da aprendizagem da Matemática é através da contação de histórias. De acordo com Café (2000, p. 3), os contadores de histórias são importantes "pela possibilidade de, em sua atuação, mediante a linguagem corporal, expressa pelo gesto e pela voz, restabelecer uma comunicação que traz enriquecimentos culturais, pois mobiliza a imaginação, o sentimento, a cognição e a criatividade". Nessa Revista Educação Online, Rio de Janeiro, n. 28, mai-ago 2018, p. 60-82 
perspectiva, Andrade e Grando (2007) acreditam que nas aulas de matemática a contação de histórias promove ludicidade, imaginação, envolvimento e criatividade, ressignificando o seu ensino.

Diferentes estudos vêm mostrando a relação entre a contação de histórias e a matemática. Dentre esses, destacamos Conti, Mourão e Belo (2014), que descrevem um relato de experiência na educação infantil. As autoras utilizaram a história Branca de Neve e os sete anões e verificaram a possibilidade de trabalho com divisão, contagem e comparação de quantidades neste nível de ensino. Além dessas autoras, Silva (2012) realizou um trabalho aproximando literatura infantil e matemática. O autor analisou a construção do conceito de multiplicação em turmas do último ano da educação infantil e no $2^{\circ}$ ano do ensino fundamental. Como resultados, destacou a formação significativa do conceito de multiplicação e de outros conceitos matemáticos, tais como proporcionalidade, reversibilidade e comutatividade.

Diante do exposto, percebe-se como é importante refletir sobre o ensino da matemática e pensar em alternativas diversificadas que possam ressignificar o ensino e a aprendizagem de seus conteúdos. Sendo assim, este artigo tem como proposta discutir a análise da relação entre literatura infantil e matemática, abordando especificamente o ensino de combinatória, tendo como parâmetro de análise um processo de formação continuada realizado com uma professora do $2^{\circ}$ ano do ensino fundamental e o modo como esta, com base nas situações, invariantes e representações simbólicas ${ }^{1}$ da combinatórias, trabalhou tal conceito com sua turma.

\section{Teoria dos campos conceituais e a combinatória}

No campo conceitual das estruturas multiplicativas encontra-se a Combinatória. Vários estudos (AZEVEDO e BORBA, 2012; PESSOA e SANTOS, 2012; PESSOA e SILVA, 2013; e PESSOA e SANTOS, 2015) vêm destacando a importância do trabalho dessa área da matemática, além de os PCN (BRASIL, 1997) e de os Parâmetros Curriculares de Matemática de Pernambuco (PERNAMBUCO, 2012)

\footnotetext{
1 Situações, invariantes e representações simbólicas são partes do tripé que forma o conceito, de acordo com Vergnaud (1986) e serão discutidos mais adiante.
}

Revista Educação Online, Rio de Janeiro, n. 28, mai-ago 2018, p. 60-82 
apontarem a necessidade de tal conteúdo ser trabalhado desde os anos iniciais da escolarização.

As mudanças constantes ocorridas na sociedade trazem a necessidade de pensarmos em um processo de inovação e remodelação do ensino, tornando-o mais significativo. Nessa perspectiva, alguns estudos vêm mostrando como o ensino de matemática, especificamente o ensino da combinatória, pode ser desenvolvido em sala de aula. Dentre estes estudos, destacamos Azevedo e Borba (2012), que, analisando a contribuição do uso do software Árbol para a compreensão de problemas combinatórios Pessoa e Santos (2012) e Pessoa e Silva (2013), verificaram o resultado de um processo de intervenção, baseado nas situações, invariantes e representações simbólicas da Combinatória em turmas de $5^{\circ}$ ano e 9o ano do ensino fundamental, respectivamente, e Pessoa e Santos (2015), que trabalharam com o uso do material manipulável no processo de ensino da Combinatória.

Segundo Vergnaud (1986), o conhecimento está organizado em campos conceituais, sendo as estruturas multiplicativas um campo conceitual da matemática. Ainda de acordo com o teórico, o domínio de um campo conceitual por um sujeito se dá em um largo período de tempo o que indica a importância do trabalho com as diferentes situações combinatórias durante toda vida escolar.

De acordo com a teoria dos campos conceituais de Vergnaud, há três dimensões fundamentais para formação do conceito: (1) o conjunto de situações que dão significado ao conceito (S); (2) as relações e propriedades invariantes (I) e (3) o conjunto das representações simbólicas utilizadas para a resolução do problema (R). Todas essas dimensões devem ser consideradas no processo de ensino e aprendizado de qualquer conceito.

Com base na teoria de Vergnaud, Pessoa e Borba (2009) organizaram os problemas que envolvem o raciocínio combinatório e as propriedades invariantes abrigadas em cada tipo de problema. A seguir, no Quadro 1, com base em com base em Pessoa e Borba (2009), apresentamos as situações presentes na combinatória (produto cartesiano, arranjo, permutação e combinação) e seus respectivos invariantes. 
Quadro 01 - Situações e Invariantes da Combinatória

Produto Cartesiano: (1) dois (ou mais) grupos diferentes serão combinados para construir um novo grupo; (2) a ordem dos elementos poderá ou não gerar novas possibilidades.

Arranjo: (1) de um grupo maior serão selecionados elementos que constituirão os subgrupos; (2) a ordem e a escolha dos elementos geram novas possibilidades.

Permutação: (1) todos os elementos do grupo são utilizados, cada um apenas uma vez para formar os novos grupos; (2) a ordem dos elementos do grupo gera novas possibilidades.

Combinação: (1) de um grupo maior serão selecionados elementos que constituirão os subgrupos; (2) a ordem dos objetos não gerará novas possibilidades.

Fonte: Pessoa e Borba (2009)

As autoras ainda destacam que as representações simbólicas, ou seja, as possíveis estratégias utilizadas para resolução de uma situação combinatória, seriam as árvores de possibilidades, diagramas, fórmulas, quadros, listagens, entre outras.

Diante do exposto, acreditamos ser necessário refletir sobre como vem se dando o processo de ensino da combinatória nos anos iniciais do ensino fundamental.

\section{O conhecimento docente à luz de alguns autores}

Uma inquietação constante no meio educacional é a formação de professores. De acordo com Pires (2001), Curi e Pires (2004), e reafirmado por Albuquerque e Gontijo (2013), é preciso repensar a formação docente. Rocha (2011) defende que é importante pensar que a formação de professores é um processo ininterrupto, sistemático, organizado e complexo, que permanece durante todo o caminho percorrido na docência.

Os autores supracitados, refletindo sobre essa temática, acreditam que há competências básicas a esses profissionais da educação, seja qual for o nível de ensino em que atuem. Entendemos tais competências como os conhecimentos necessários à docência, identificados por pesquisadores como Tardif (2008), Shulman (2005) e Gauthier (1998).

Nesse contexto, Cardim e Grando (2008) defendem que a formação, seja ela inicial ou continuada, é um processo complexo, uma vez que as competências acima citadas, juntamente com a prática docente, estão atreladas ao processo de aprendizagem profissional. 
Alguns autores dissertam sobre os conhecimentos e saberes necessários à docência (FREIRE, 1996; GAUTHIER, 1998; SHULMAN, 2005; e TARFID, 2008), contudo, a seguir, aprofundaremos a discussão que Shulman (2005) traz sobre o conhecimento docente e sobre as contribuições deste autor que foram consideradas por Ball, Thames e Phelps (2008), ao refletirem sobre os conhecimentos necessários especificamente de professores que ensinam Matemática.

De acordo com Lee Shulman (2005), vários autores, por gerações, discutem quais as competências, habilidades e conhecimentos necessários que o professor precisa ter para ensinar. Nessa perspectiva, o autor considera que é necessária a construção de uma base do conhecimento (knowledge base). Esta, segundo Shulman (2005), é composta por sete categorias: 1) conhecimento do conteúdo; 2) conhecimento didático geral - princípios e estratégias de organização da classe, que transcendem o âmbito da disciplina; 3) conhecimento do currículo materiais e programas que sirvam como ferramentas de auxílio para o docente; 4) conhecimento didático do conteúdo - combinação de matéria e conteúdo, constituindo uma esfera exclusiva dos professores; 5) conhecimento dos alunos e suas características; 6) conhecimento dos contextos educativos - abrange desde o funcionamento da sala de aula, a gestão e financiamento dos distritos escolares até o caráter das comunidades e culturas; 7) conhecimento dos objetivos, das finalidades e dos valores educativos, e de seus fundamentos filosóficos e históricos.

Entre as classificações elencadas por Shulman (2005) como formadoras da base do conhecimento, destaca-se o conhecimento didático do conteúdo. Para o autor, esta categoria "representa a mistura entre a matéria/disciplina e a didática" ( $p$. 12), uma vez que este conhecimento reflete o modo de pensar do professor diante de determinados temas e problemas, adaptando-os de acordo com os interesses e capacidades dos alunos. E, além disso, Shulman (2005) ainda destaca que é este conhecimento que distingue a compreensão de um especialista da área a respeito de um determinado assunto e a de um professor.

A partir dos estudos de Shulman (2005), Ball, Thames e Phelps (2008) investigaram os conhecimentos necessários para o ensino da matemática. Os pesquisadores estabeleceram uma estreita relação entre os principais conhecimentos que Lee Shulman destaca para a docência, o conhecimento do Revista Educação Online, Rio de Janeiro, n. 28, mai-ago 2018, p. 60-82 
conteúdo e o conhecimento didático do conteúdo. No entanto, para eles, no que diz respeito ao ensino da matemática, há algumas subdivisões intrínsecas a estes conhecimentos.

Ball, Thames e Phelps (2008) elencaram seis domínios importantes no processo de ensino da matemática: o conhecimento comum do conteúdo, conhecimento horizontal do conteúdo e conhecimento especializado do conteúdo; conhecimento do conteúdo e os alunos, conhecimento do conteúdo e o ensino e conhecimento do conteúdo e o currículo. Relacionam os três primeiros conhecimentos aqui listados como domínios pertencentes ao conhecimento do conteúdo e os três últimos ao conhecimento didático do conteúdo, identificado por Shulman (2005). A seguir, diferenciamos mais detalhadamente cada um desses domínios.

O conhecimento comum do conteúdo é definido como o conhecimento matemático e habilidade usada em ambientes, sem focar necessariamente o ensino. Em suma, os professores devem ser capazes de fazer o trabalho que eles atribuem aos seus alunos, ele não é específico para o trabalho de ensino. O segundo domínio, o conhecimento horizontal do conteúdo, é entendido como a consciência de como os temas matemáticos estão relacionados à extensão da Matemática incluída no currículo. Como exemplo, os autores citam como os professores precisam saber como a Matemática que ensinam está relacionada com a Matemática que os alunos irão aprender na terceira série, para ser capazes de definir a base matemática que virá depois. O conhecimento especializado do conteúdo, o terceiro domínio, é o conhecimento matemático e habilidade tipicamente necessários para o ensino. Outro domínio, o quarto, é o conhecimento do conteúdo e dos alunos, esse é o conhecimento que combina saber sobre os alunos e saber sobre matemática. Os professores devem antecipar o que os alunos tendem a pensar e suas possíveis dúvidas. Ao escolher um exemplo, os professores precisam prever o que os alunos vão achar interessante e motivador. Para eles, os professores devem também ser capazes de ouvir e interpretar os estudantes. Cada uma dessas tarefas requer uma interação entre o entendimento matemático específico e familiaridade com os alunos e seu pensamento matemático. O quinto domínio é o conhecimento do conteúdo e ensino, que combina o conhecimento sobre o ensino e o saber sobre a matemática. Os docentes escolhem os exemplos Revista Educação Online, Rio de Janeiro, n. 28, mai-ago 2018, p. 60-82 
necessários para começar e que exemplos usar para levar os alunos a aprenderem o conteúdo mais profundamente. Cada uma dessas tarefas requer uma interação entre a compreensão da matemática específica e um entendimento do pedagógico e as questões que afetam a aprendizagem do aluno. As demandas de ensino exigem a intersecção do conhecimento do conteúdo e ensino. Por fim, sobre o conhecimento do conteúdo e o currículo, Ball, Thames e Phels (2008) não fazem uma explanação profunda, contudo, questionam se esta seria uma categoria isolada, assim como as demais, ou se estaria presente no domínio referente ao conhecimento do conteúdo e do ensino. Porém, certamente, o estudo sobre este conhecimento se faz importante, a fim de que diferentes conteúdos matemáticos sejam realocados para outros níveis de ensino, como é o caso da combinatória, cujo ensino defendemos que seja efetuado durante toda escolarização.

Diante das classificações aqui apresentadas dos conhecimentos docentes, acreditamos ser de extrema relevância a discussão de como essas competências são mobilizadas durante a formação do professor, seja ela inicial ou continuada.

\section{Matemática e literatura infantil: uma relação possível}

Acreditamos, assim como os Parâmetros Curriculares Nacionais (BRASIL, 1997) e Smole, Diniz e Cândido (2000), entre outros autores, que o trabalho matemático realizado em sala de aula deve ser contextualizado e que a resolução de problemas, como também destacado por Borba (2010), possibilita o desenvolvimento de vários conceitos, seja na matemática ou em demais áreas de ensino.

Nesse sentido, defendemos, assim como Smole, Rocha, Cândido e Stancanelli (1996), a realização do trabalho interligado entre a Matemática e a Linguagem, sendo esta aproximação necessária durante todos os anos de escolaridade.

As autoras ressaltam que:

através da conexão entre a Literatura e Matemática, o professor pode criar situações na sala de aula que encorajem os alunos a compreenderem e se familiarizarem mais com a linguagem matemática, estabelecendo ligações cognitivas entre a linguagem materna, conceitos da vida real e a linguagem matemática formal, dando oportunidades para eles escreverem e falarem sobre o vocabulário matemático, além de desenvolverem habilidades de formação e resolução de problemas enquanto desenvolvem noções e conceitos matemáticos. (SMOLE et al., 1996, p. 30) 
Como destacado por elas, uma das possibilidades dessa relação existente é a resolução de problemas através da contação de histórias. As histórias clássicas podem ser usadas como um recurso didático, trazendo significado e prazer durante as atividades e dando sentido aos conceitos matemáticos trabalhados.

O estudo realizado por Aguiar e Grando (2007) apontou que um trabalho desenvolvido com resolução de problemas a partir das histórias infantis faz com que o conceito escolhido através da situação-problema seja melhor apropriado, uma vez que as crianças fazem uma assimilação particular. Rodrigues e Souza (2007) também propuseram uma atividade de matemática a partir de textos da literatura infantil e puderam verificar que essa opção se faz eficiente no processo de aprendizagem, ajudando na construção do conhecimento dos alunos.

Ainda nessa perspectiva, Andrade e Grando (2007), Melo (2015) e Rysdyk (2010) também desenvolveram pesquisas que se propuseram a analisar o efeito de aulas que visavam ao trabalho matemático a partir da literatura infantil. Rysdyk (2010) trabalhou diferentes histórias infantis e alguns conceitos matemáticos que poderiam estar atrelados a elas. Uma dessas histórias foi Os três porquinhos, sendo destacado o trabalho com adição, subtração, noção de dezena, classificação, seriação, sequência numérica, regularidades do sistema de numeração decimal e figuras geométricas planas, além do trabalho com a dobradura. Contudo, não foi realizado o trabalho com a Combinatória, o que será aqui apresentado e analisado.

\section{Objetivos e método}

Ressaltamos que o presente artigo é um recorte de um trabalho maior (ASSIS, 2014), o qual investigou o efeito de uma formação continuada sobre Combinatória nas reflexões e na prática da professora pesquisada, tendo como base as situações, invariantes e representações simbólicas de cada tipo de problema. De modo mais específico, verificou quais foram as mudanças de conhecimento demonstradas pela professora após a intervenção.

A proposta de intervenção foi realizada em seis encontros, com cinco professoras, embora tenhamos analisado apenas uma docente $(P)$, a qual participou de todo o processo de formação. Os encontros com as cinco professoras foram divididos da seguinte forma: o primeiro foi voltado para a discussão e reflexão da Combinatória como um conteúdo a ser trabalhado em sala de aula, à luz da Teoria Revista Educação Online, Rio de Janeiro, n. 28, mai-ago 2018, p. 60-82 
de Vergnaud (1996), abordando as situações e invariantes dos problemas combinatórios, seguido do segundo encontro, que abordou a produção dos diferentes problemas combinatórios. No terceiro encontro, foram trabalhadas as diferentes representações simbólicas possíveis para a resolução dos problemas combinatórios, assim como a ideia de sistematização dos procedimentos de resolução e generalização/percepção de regularidade. Ainda nesse encontro, foi elaborado um planejamento de aula direcionado aos alunos dos anos iniciais de escolarização, abordando o tema combinatória e suas diferentes dimensões, para que fosse aplicado em sala de aula. No quarto encontro aconteceu a aplicação do planejamento de aula pelas professoras, com observação da pesquisadora. Ao término da aula, ocorreu uma entrevista semiestruturada, a fim de verificar as análises realizadas, individualmente, pela docente, sobre a aula ministrada. Em seguida, houve mais um encontro, o quinto, para que as professoras participantes do processo de formação pudessem trazer análises e discussões de sua prática diante de todo o processo realizado durante a formação. No último encontro, aconteceu mais um momento de observação de aula, seguida de uma entrevista semiestruturada, como no quarto encontro. As observações de aula tiveram os seguintes eixos de análise: relação do professor com o conhecimento dos alunos sobre o conteúdo; relação do professor com o conteúdo; e recursos didáticos utilizados em sala de aula. Todas as aulas foram filmadas e posteriormente transcritas e analisadas.

Destacamos, no atual estudo, a aula ministrada por uma professora dos anos iniciais do Ensino Fundamental, durante o sexto encontro do processo de formação continuada citado acima, sobre a temática em questão.

Diante do exposto, temos como objetivo central deste artigo discutir a análise de uma aula de combinatória, tendo como base o trabalho desenvolvido com resolução de problemas a partir de uma história infantil, verificando, de modo mais específico, se as situações, invariantes e representações simbólicas foram trabalhadas e se o contexto da contação de histórias favorece o ensino e a aprendizagem da matemática, especificamente do conteúdo da Combinatória.

A pesquisa foi realizada com uma professora do $2^{\circ}$ ano do ensino fundamental de uma escola pública do município de Olinda. A mesma possui formação em pedagogia e leciona há 12 anos. Sua turma conta com 19 alunos. A Revista Educação Online, Rio de Janeiro, n. 28, mai-ago 2018, p. 60-82 
escola, da qual a professora faz parte, trabalha com turmas de educação infantil e ensino fundamental I, possuindo ao todo 14 turmas, sendo sete pelo turno da manhã e sete, à tarde.

\section{Resultados obtidos: apresentação e análise}

Apresentamos a aula de uma professora que atua em uma turma do $2^{\circ}$ ano do Ensino Fundamental. Para a observação da aula, foi utilizado um roteiro, com três eixos de análise: relação do professor com o conhecimento dos alunos sobre o conteúdo, relação do professor com o conteúdo, recursos utilizados em sala.

A professora ${ }^{2}$ analisada trabalhou com a Combinatória, especificamente com o problema de arranjo. Em um contexto da história infantil Os três porquinhos, a docente apresentou uma situação-problema na qual iriam ser premiados dois porquinhos com duas moradias, sendo o primeiro lugar com uma casa na árvore e o segundo lugar com um apartamento. A seguir, apresentamos a contextualização realizada pela docente.

P: Era uma vez três porquinhos: Heitor, Cícero e Prático. Eles moravam na casa de sua mãe, só que a mãe percebeu que os filhos estavam muito grandes e disse: "Meus filhos, vocês estão bem grandinhos, precisam começar a viver sozinhos". E a mãe continuou: "Cada um vai ter que providenciar sua casinha, mas lembrem-se, na floresta tem lobo mal". Os porquinhos foram morar na floresta e eles ficaram super animados porque iam viver só.

Heitor, muito agoniado, pensou logo: vou fazer minha casa com o que primeiro encontrar. Ele saiu passeando pela floresta e o que encontrou? Palha! Aí os irmãos falaram: "Heitor, esse material é muito fraco pra você fazer sua casa". Heitor agoniado foi logo dizendo: "Ah, mas eu estou apressado, quero fazer minha casa assim para poder brincar". E assim ele a fez!

Cícero e Prático continuaram passeando. Aí Cícero encontrou um monte de madeira no meio do caminho e foi logo resolvendo: "Vou fazer minha casa de madeira". Prático o alertou: "Esse material é muito fraco". Cícero respondeu: "Mas eu quero fazer pra quando terminar ir brincar logo". E assim ele fez. Prático continuou andando e resolveu fazer a casa de tijolo. Ele não estava preocupado em brincar não, mas em fazer uma casa segura.

Cada um ficou em sua casa quando, de repente, o lobo percebeu o cheirinho de porquinhos por lá e saiu logo passeando e encontrou a primeira casa. De quem era a primeira casa?

Alunos: Heitor.

$P: E$ a casa era feita de quê?

Alunos: Palha.

P: Isso, palha! Aí o lobo: "Quem está aí?" Heitor foi logo dizendo: "Tem ninguém não". E o lobo: "Ah, seu porquinho bobinho, você construiu sua casa de palha, eu vou só soprar e você já já estará na minha boquinha". Heitor correu tanto e foi para a

${ }^{2} \mathrm{~A}$ professora aqui analisada será identificada por $\mathrm{P}$ e a entrevistadora por $\mathrm{E}$.

Revista Educação Online, Rio de Janeiro, n. 28, mai-ago 2018, p. 60-82 
casa de Cícero. Aí ficaram os dois lá dentro, morrendo de medo! Chegou o lobo e foi logo falando: "Ahh, o cheiro está mais forte, agora são dois porquinhos que tenho aqui. Com esse material eu só faço soprar e vocês vão estar dentro da minha boca". Aí o lobo tome a soprar e os porquinhos saíram correndo para a casa de Prático. Ficaram os três juntos lá, tudo agarradinhos com medo. Quando o lobo chegou, foi logo dizendo: "Agora são três, eu vou soprar e encher minha barriguinha". O lobo soprou, soprou, mas não conseguia derrubar a casa. Ele pensou: não tem problema, eu vou subir e entrar pela chaminé. Só que Prático era muito prático, pegou uma água fervendo, colocou embaixo da chaminé e quando o lobo entrou pela chaminé, ele queimou o quê?

Alunos: $O$ bumbum.

P: Isso, o rabo! O lobo saiu desesperado e nunca mais apareceu. Aí Prático conversou com os irmãos: "Eu disse pra vocês que o material de palha e madeira não ia adiantar, era muito fraco!".

Depois disso tudo, o que aconteceu? Os outros dois ficaram sem casa! Aí a mãe dos três porquinhos apareceu e disse o seguinte: "Meus filhos, eu sei que vocês tiveram dificuldade em viver sozinhos, então eu quero presentear vocês com duas casas, pois só sobreviveu uma casa". Foi a casa de quem que sobreviveu?

Alunos: Prático.

$P: E$ a casa dele era de quê?

Alunos: Tijolo

P: Ela disse: "Eu tenho duas casas. A primeira casa é uma casa da árvore". Todos queriam a casa da árvore, pois a casa era muito alta e o lobo não ia conseguir chegar lá. Mesmo Prático tendo a casa dele, ele queria a casa da árvore. E a segunda casa que a mãe disse que ia dar era um apartamento. Os porquinhos ficaram interessados, mas não tanto como na casa da árvore. Então, lá vai o probleminha que vou lançar com vocês, pois a mãe ficou com bastante dúvida aí vocês vão ter que ajudar.

$[\ldots]$

Então vocês vão tentar pensar as formas deles ganharem, quais possibilidades que a gente vai ter para os porquinhos ganharem os prêmios. (Diálogo entre professora e alunos, 2014)

Consegue-se verificar que, apesar de ser a única situação-problema trabalhada na aula, a professora apresenta um exemplo de arranjo contextualizado, no qual explicita os invariantes contidos neste tipo de problema. Entende-se que a situação apresentada seja de arranjo, uma vez que a casa da árvore é referente ao primeiro lugar, sendo o prêmio mais desejado pelos três porquinhos, e o apartamento ficaria como o prêmio para o segundo lugar, não demonstrando tanto interesse por parte dos porquinhos. Prático, o porquinho que não perdeu sua casa, também entrou na disputa, pois queria ganhar a casa da árvore, mesmo tendo a de tijolos.

Desta forma, além da professora explicitar os invariantes, ela estabeleceu uma relação com a história, adaptando-a ao contexto de ensino e, assim, conseguiu contextualizar o problema. Ao término da contação da história, a docente questiona 
os alunos sobre os elementos existentes no problema e os registra no quadro (ver Figura 1), fazendo-os perceber o raciocínio que está contido neste tipo de situação.

Figura 1 - Registro realizado no quadro, pela professora, dos elementos existentes na situação-problema apresentada na aula

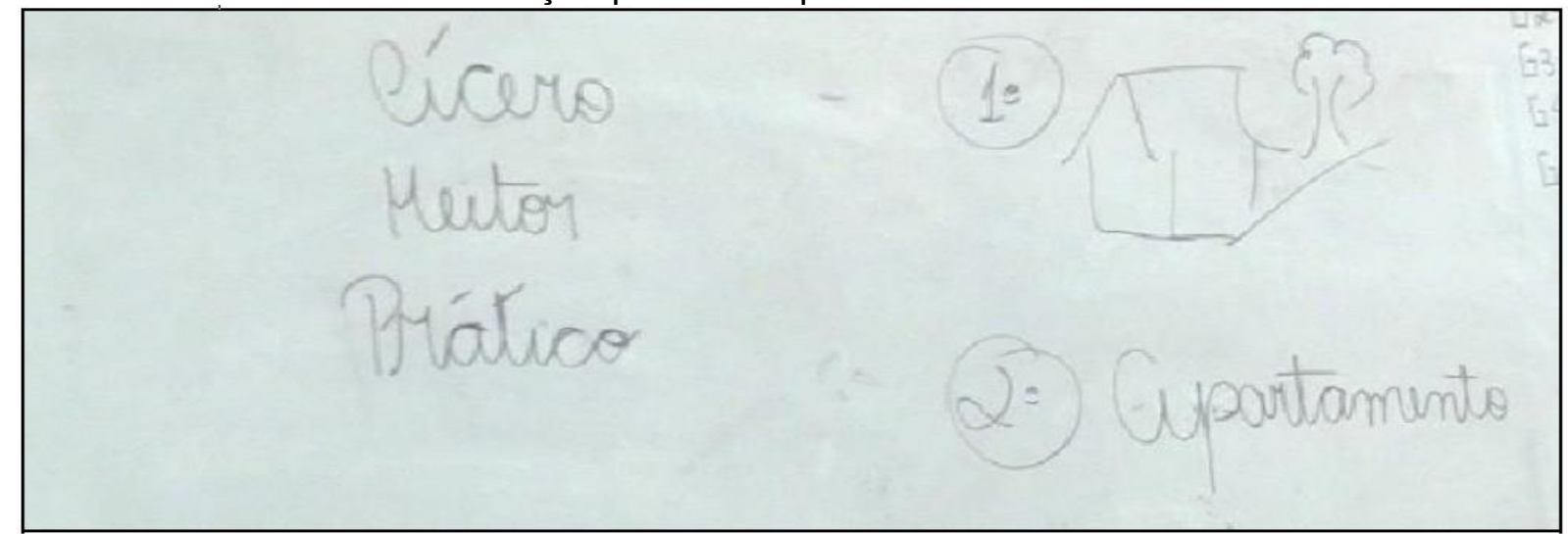

Fonte: ASSIS (2014)

P: Olha só, qual é o primeiro prêmio?

Alunos: A casa na árvore [a professora desenhou no quadro o primeiro prêmio].

$\mathrm{P}$ : E o segundo prêmio?

Alunos: Apartamento [a professora escreveu no quadro o segundo prêmio].

$P:$ Quem vai participar dessa premiação?

Alunos: Cícero e Heitor.

$\mathrm{P}$ : Só eles dois?

Alunos: Não, e Prático!

P: Isso, Prático já tinha a casa, mas Prático queria o quê?

Alunos: A casa na árvore.

$P$ : Então vocês vão tentar pensar as formas deles ganharem, quais possibilidades que a gente vai ter pra ganharem os prêmios. Vou entregar os porquinhos pra vocês [entrega em material manipulável - ficha desenhada - cada porquinho para cada grupo] e os prêmios [entrega os dois prêmios em material manipulável - ficha desenhada ] e uma folha de papel pra vocês escreverem, certo? (Diálogo entre professora e alunos, 2014)

Nesse momento da aula, além da história, a professora utiliza-se do desenho para iniciar uma resolução e apresenta o material manipulável para os alunos, a fim de que este material auxilie na resolução do problema (ver Figura 2). 
Figura 2 - Material manipulável - ficha desenhada - utilizado na aula

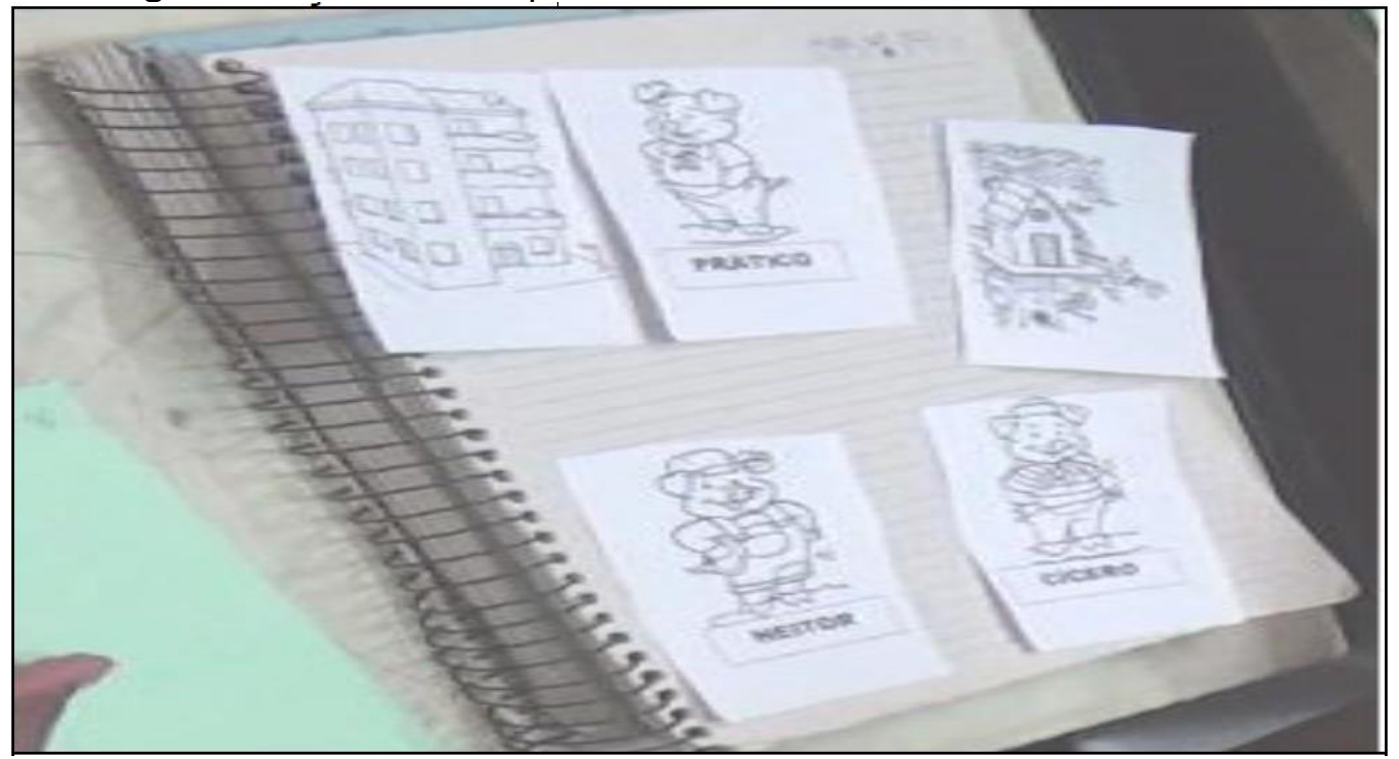

Fonte: ASSIS (2014)

Foram formados grupos em sala para resolverem juntos a situação apresentada. Segundo a professora, cada grupo tinha alunos de diferentes níveis, a fim de que eles se auxiliassem. Alguns grupos de alunos, ao começarem a resolver o problema apresentado, conseguiram listar algumas possibilidades, contudo, determinados grupos não perceberam que a troca da ordem dos elementos iria gerar novas possibilidades.

A professora foi de grupo em grupo auxiliando e direcionando os alunos a colocarem as imagens da casa na árvore de um lado da folha de papel e o apartamento do outro lado, para que embaixo colocassem as possibilidades do primeiro e do segundo lugar, tornando mais fácil a visualização. A partir desta intervenção da docente, observamos que os alunos conseguiram perceber melhor as possibilidades existentes. 
Figura 3 - Alunos resolvendo a situação-problema apresentada pela docente

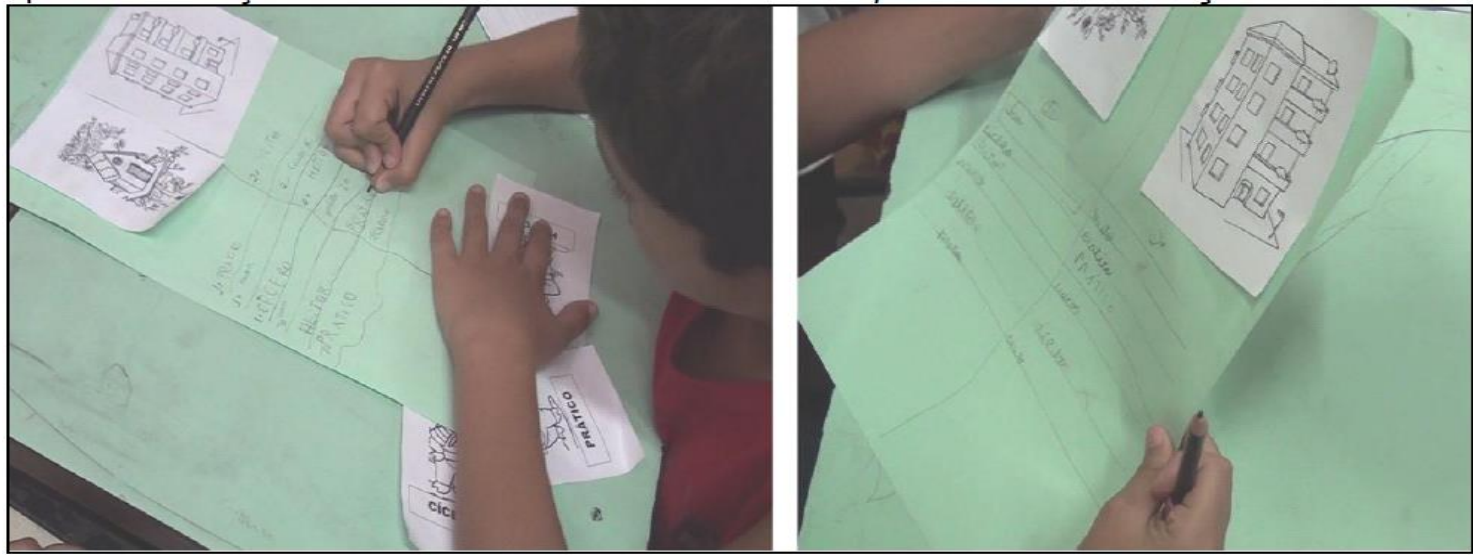

Fonte: ASSIS (2014)

Apesar de o foco da presente pesquisa não ser o aluno e sim o professor, não pudemos deixar de verificar que os alunos estavam compreendendo as relações existentes no tipo de situação trabalhada em sala de aula.

Ao perceber que todos os grupos já haviam terminado, a docente fez, no quadro, o registro coletivo das possibilidades existentes.

Figura 4 - Registro realizado pela professora do total de possibilidades da situaçãoproblema apresentada na aula

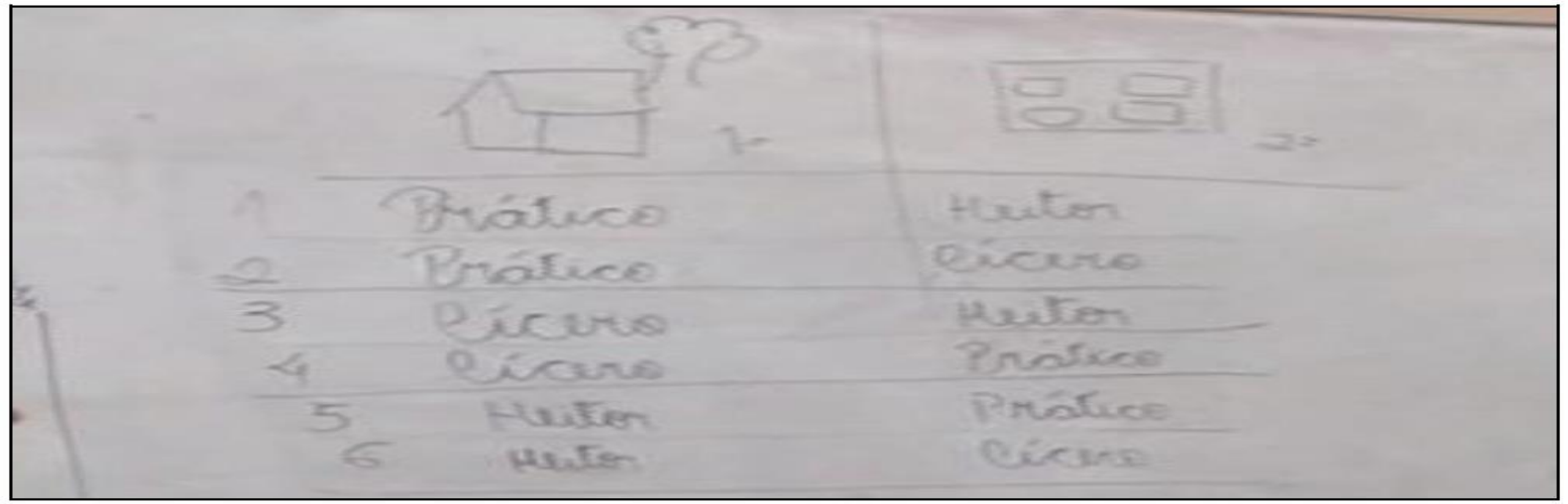

Fonte: ASSIS (2014)

P: Qual é o primeiro prêmio?

Alunos: Casa da árvore

P: E o segundo?

Alunos: apartamento

[A professora desenha no quadro da maneira que orientou os alunos a fazerem, colocando a imagem do primeiro prêmio de um lado e do segundo prêmio do outro lado da folha. Em seguida, sinaliza os desenhos com $1^{\circ}$ e $2^{\circ}$.]

P: Qual a primeira possibilidade?

Alunos: Prático e Heitor

$\mathrm{P}$ : Prático pode ser com Heitor e pode ser com mais quem?

Alunos: Cícero!

P: E Cícero, pode ser com quem?

Alunos: Cícero e Heitor e Cícero e Prático. 
P: E Heitor?

Alunos: Heitor e Prático e Heitor e Cícero. (Diálogo entre professora e alunos, 2014)

Vale ressaltar que a docente realizou o registro de forma sistematizada, utilizando-se de uma listagem e sinalizando os respectivos prêmios como primeiro e segundo lugar, ou seja, enfocando o invariante da ordem.

Pôde-se perceber que nesta aula a docente só trabalhou um tipo de problema combinatório, contudo, levantou os invariantes contidos neste tipo de problema, 0 que facilitou a compreensão dos alunos. A docente utilizou-se da listagem sistemática como um tipo de representação simbólica válida para a resolução de problemas combinatórios, além do desenho, e utilizou-se ainda do material manipulável como um recurso viável no auxílio da resolução desses problemas.

O conhecimento da combinatória foi perceptível durante a aula, pois havia o domínio da situação e de suas características, assim como das representações simbólicas empregadas. A docente fez uso, ainda, do conhecimento do conteúdo e de seus alunos ${ }^{3}$ e do conhecimento do conteúdo e de seu ensino ${ }^{4}$, que fazem parte do conhecimento didático do conteúdo, como defendido por Ball, Thames e Phelps (2008), uma vez que contextualizou a situação-problema trabalhada em sala a partir de uma história da literatura infantil, com a qual seus alunos têm familiaridade, motivando-os.

Ao término dessa aula, foi realizada uma entrevista semiestruturada, a fim de que a docente pudesse analisar a aula por ela ministrada. Ao pedir sua opinião sobre as atividades realizadas, a docente relata ter se sentido mais à vontade, pois, diferente da aula ministrada no quarto encontro do processo formativo, ela conseguiu realizar um planejamento mais organizado, no qual sabia o passo a passo da aula.

E: O que você achou dessa aula?

P: Eu acho que vim mais preparada. Eu tinha preparado tudo em casa, sabia direitinho o que ia fazer, já tinha tudo esquematizado. (Diálogo entre professora e entrevistadora, 2014)

\footnotetext{
${ }^{3} \mathrm{O}$ conhecimento do conteúdo e os alunos é o que combina saber sobre os alunos e saber sobre matemática. Os professores devem antecipar o que os alunos tendem a pensar e as possíveis dúvidas. Ao escolher um exemplo, os professores precisam prever o que os alunos vão achar interessante e motivador.

${ }^{4} \mathrm{O}$ conhecimento do conteúdo e ensino combina o conhecimento sobre o ensino e o saber sobre a matemática. $O$ professor deve escolher quais exemplos para começar e que exemplos usar para levar os alunos a aprender o conteúdo mais profundamente.
}

Revista Educação Online, Rio de Janeiro, n. 28, mai-ago 2018, p. 60-82 
Ao ser solicitado que ela comparasse o rendimento dos alunos nas duas aulas aplicadas durante o processo formativo, a professora reconheceu que os alunos conseguiram se sair melhor na primeira aula, onde foi trabalhada a situação de produto cartesiano. Acreditamos que essa análise realizada pela professora está em consonância com os resultados de alguns estudos (PESSOA, 2009 e AZEVEDO E BORBA, 2012), os quais vêm apontando que os alunos dos anos inicias têm mais facilidade na compreensão de problemas de produto cartesiano do que nas demais situações.

E: Nessa aula, você acredita que teus alunos se saíram melhor que na primeira aula? Ou o mesmo nível ou tiveram mais dificuldade?

$P$ : Eu acho que nessa [referindo-se à Aula 2] eles tiveram um pouquinho mais de dificuldade pra engatar, tiveram dificuldade pra saber o que era pra fazer. Então eu fui dando o caminho, fui colar as casinhas já para eles perceberem que tinha que fazer uma tabela pra ficar mais fácil de resolver. Mas eu não dizia 'vá fazer a tabela'. Eu colava os desenhos para eles perceberem e perguntava: 'Quem é primeiro? Quem é segundo? Vejam aí quais as possibilidades que podem ter'. (Diálogo entre professora e entrevistadora, 2014)

Ainda fazendo uma comparação entre as duas aulas ministradas durante a intervenção proposta, a docente ressaltou a necessidade de trabalhar este conteúdo em mais aulas, falando especificamente da situação de arranjo, a qual foi trabalhada com sua turma.

E: Você acha que produto cartesiano foi mais fácil pra eles?

P: Foi, foi mais fácil. Eu acho que eles perceberam mais rápido.

$E$ : E com relação à aula de arranjo, tuas expectativas foram alcançadas?

$P$ : Esse daqui eu gostei do resultado. Eu pensei que ia demorar muito mais, fiquei até preocupada quando vi a demora e pensei 'será que eles irão alcançar?'. Mas, claro, faria mais aulas pra ter um resultado mais feliz, como no produto cartesiano, pra ter um resultado legal. Esse daqui eu vi que eles alcançaram, pois vi que no final todos conseguiram fazer, mas precisaria de mais aulas pra poderem evoluir. (Diálogo entre professora e entrevistadora, 2014)

A professora relatou, ainda na entrevista realizada após a aula, ter trabalhado antes da aula observada um exemplo de situação de arranjo. Nesta direção, buscamos verificar a análise da docente sobre este trabalho realizado em sala, mesmo que não o tenhamos observado.

$\mathrm{E}$ : Você disse que antes já tinha apresentado um problema de arranjo com eles, qual era o contexto do problema?

P: O contexto era premiação em sala de aula. O primeiro prêmio era uma bicicleta e o segundo um quebra-cabeça. Aí disse que eram 3 alunos que tiravam notas muito boas e eles tinham a possibilidade de ser o primeiro e o segundo lugar. 
P: Quando eu fiz, não fiz com que eles fizessem mesmo, eu fiz o registro no quadro, no coletivo. No coletivo, eles pensaram rapidinho. Citaram o nome de uma das três pessoas e viram as duas possibilidades, depois do outro e assim foi. Então no coletivo eles pensaram mais. [...] E no coletivo, esses que são mais atentos, falaram mais, aí os outros ficaram concordando e percebendo. Tanto que, quando dei esse problema, não pensei que ia demorar tanto. Mas como foram grupos separados, cada um no seu grupinho, os que eram mais espertos não puderam ajudar um ao outro, porque estavam separados. Mas mesmo assim, depois que fui de grupo em grupo, eu fui vendo que eles foram desenvolvendo. (Diálogo entre professora e entrevistadora, 2014)

Vale ressaltar, a partir desse extrato, que os alunos, ao resolverem coletivamente a primeira situação-problema apresentada na sala, a qual não fez parte da aula observada, realizaram coletivamente a listagem das possibilidades, fazendo-a de modo sistemático.

Diferente da primeira aula observada, a docente se sentiu mais segura na aplicação da segunda, aqui relatada, levantando poucas mudanças que poderiam melhorar o processo de ensino e aprendizagem.

$\mathrm{E}:$ Você acha que o planejamento deu conta para o que você queria?

$P$ : Eu estou tranquila quanto ao que eu produzi hoje.

$\mathrm{E}:$ Você mudaria alguma coisa?

$\mathrm{P}: \mathrm{O}$ professor sempre quer mudar alguma coisa, né? No contexto, no geral, eu acho que foi bem, separei um tempo pra fazer mesmo o planejamento, foi uma coisa de $3 \mathrm{~h}$, pensando, pesquisando... Poderia ser até que eu mudasse alguma coisa, acrescentando outro problema, pra eles fazerem, como se fosse uma avaliação, pra ver se eu desse o segundo problema se eles já fariam com mais facilidade. (Diálogo entre professora e entrevistadora, 2014)

Quando questionada sobre a escolha do tipo de problema para trabalhar na aula em questão, a docente ressaltou a dificuldade de encontrar materiais para auxiliar os professores a construírem aulas sobre a combinatória, o que condiz com o que Barreto, Amaral e Borba (2007) apresentam como um dos resultados de pesquisa, que os manuais do professor dos livros didáticos dos anos iniciais do ensino fundamental não trazem orientações ao docente sobre o trabalho com problemas combinatórios.

E: Dentre os outros três problemas que restaram (arranjo, permutação e combinação), já que você tinha feito a primeira aula de produto cartesiano, por que você escolheu arranjo? Ou foi aleatório?

P: Quando eu fui fazer a pesquisa pra aula, eu sabia que tinha que tirar o cartesiano, tinha que ver um dos outros três. Aí li, reli, li os exemplos que tinha anotado durante a formação, mas não encontrei nada, nada dos outros três. Aí foi quando eu fiquei pensando num contexto pra envolver o problema. Foi aí que pensei na história dos 
três porquinhos e pensei que podia fazer a premiação das casas e encaixei com o problema. Foi assim que consegui fazer.

E: Foi difícil fazer o planejamento?

P: Foi, muito. Tive que arrumar primeiro a história pra encaixar o problema. Eu tinha até pensado em fazer outro problema, como permutação, mas não consegui pensar. Foi bem complicado, pode registrar lá no seu artigo, como é difícil, tem que suar muito pra colocar isso na prática. Só achava coisa de nível muito alto, o que me salvou foram os três porquinhos [risos]. (Diálogo entre professora e entrevistadora, 2014)

Assim como discutido em algumas pesquisas anteriores e no referencial teórico desta, faltam materiais que auxiliem os professores na organização de aulas sobre a Combinatória, além da própria formação quanto a este conteúdo.

A partir da aula ministrada pela docente e da entrevista que sucedeu à aula, constatamos que o conhecimento especializado do conteúdo ${ }^{5}$ e o conhecimento didático do conteúdo ${ }^{6}$, discutidos por Ball, Thames e Phelps (2008) e por Shulman (2005), respectivamente, foram bem articulados, uma vez que a professora aqui pesquisada obteve domínio das situações combinatórias propostas em suas aulas e conseguiu trabalhar de forma eficaz e didática tais problemas combinatórios com sua turma.

\section{Considerações finais}

Entendendo a necessidade de uma constante pesquisa e averiguação acerca da formação docente, o presente artigo discutiu possibilidades metodológicas acerca do ensino da matemática, especificamente, a respeito do conteúdo da combinatória, desenvolvidas por uma professora do $2^{\circ}$ ano do ensino fundamental, após participar de um processo de formação continuada baseado nas situações, invariantes e representações simbólicas de tal conteúdo. A proposta aqui analisada foi desenvolvida a partir de uma situação-problema, baseada em uma história da literatura infantil.

Verificou-se, também, que a professora realizou um trabalho articulando diferentes áreas (matemática e literatura infantil), trazendo um contexto significativo

\footnotetext{
${ }^{5} \mathrm{O}$ conhecimento especializado do conteúdo é o conhecimento matemático e habilidade única ao ensino. Um exame atento revela que este é o conhecimento matemático não tipicamente necessário para outros fins a não ser o ensino.

6 O conhecimento didático do conteúdo reflete o modo de pensar do professor diante de determinados temas e problemas, adaptando-os de acordo com os interesses e capacidades dos alunos. Constituindo-se uma esfera exclusiva dos professores.
}

Revista Educação Online, Rio de Janeiro, n. 28, mai-ago 2018, p. 60-82 
para a sala de aula, despertando, assim, a atenção e o interesse dos alunos. Ao realizar a proposta da atividade para a turma, e iniciar os questionamentos, os alunos logo realizaram inferências acerca do que estava sendo perguntado, uma vez que já conheciam a história que estava por trás da situação-problema lançada. De acordo com Café (2000), Andrade e Grando (2007), Silva (2012) e Conti, Mourão e Belo (2014), o trabalho da Matemática atrelado à contação de histórias é uma alternativa diversificada que ressignifica o ensino da matemática, trazendo ludicidade, imaginação e criatividade aos alunos.

Ressaltamos a resolução de problemas com os alunos como uma forma de ensino válida utilizada pela docente durante sua aula, a qual se relaciona com o ensino de Combinatória e está ligada ao conhecimento didático, como observado por Rocha (2011). Esta forma de ensino foi utilizada em pesquisas de intervenção (PESSOA E SANTOS, 2012; AZEVEDO E BORBA 2012; PESSOA E SILVA, 2013), com alunos dos anos iniciais e finais e, junto com o destaque do tripé de Vergnaud (1986, 1996) - situações, invariantes e representações, foi um procedimento bastante válido no processo de ensino e aprendizagem da Combinatória.

Destacamos, ainda, que após alguns encontros e reflexões acerca da Combinatória, a professora pesquisada fez uso de diferentes representações na aula ministrada, como a listagem sistematizada, desenho e uso do material manipulável como recurso facilitador para o processo de ensino e aprendizagem. Essa ideia corresponde ao que Ball, Thames e Phelps (2008) classificam como o conhecimento do conteúdo e seus alunos, uma vez que a docente buscou verificar qual seria a melhor forma de trabalhar o conteúdo com seus alunos, adequando-o à realidade deles.

Verificamos, então, que, após o processo de formação continuada do qual a professora participou, a mesma conseguiu elaborar e ministrar uma aula trabalhando a combinatória, especificamente a situação de arranjo, tendo como base uma situação-problema apresentada a partir de uma história da literatura infantil, contribuindo para um ensino e uma aprendizagem mais significativa e diversificada. 


\section{Referências bibliográficas}

ALBUQUERQUE, Leila Cunha de; GONTIJO, Cleyton Hércules. A complexidade da formação do professor de matemática e suas implicações para a prática docente. Espaço Pedagógico, v. 20, n. 1, p. 76-87, jan-jun 2013.

ANDRADE, Débora de Oliveira; GRANDO, Regina Célia. Contando histórias nas aulas de Matemática: produção/mobilização de conceitos na perspectiva da resolução de problemas. In: REUNIÃO DA ANPED, 30., 2007, Caxambú. Disponível em:

<http://www.ufrrj.br/emanped/paginas/conteudo_producoes/docs_30/contando.pdf>. Acesso em: 15 set 2016.

ASSIS, Adryanne M. R. Barreto de Assis. Conhecimentos de combinatória e seu ensino em um processo de formação continuada: reflexões e prática de uma professora. Dissertação (Mestrado em Educação Matemática e Tecnológica) UFPE, Recife, 2014.

AZEVEDO, Juliana; BORBA, Rute. O ensino da combinatória por meio da construção de árvores de possibilidades com e sem o uso do software Diagramas de Árbol. In: ENCONTRO BRASILEIRO DE ESTUDANTES DE PÓS-GRADUAÇÃO EM EDUCAÇÃO MATEMÁTICA, 16., 2012, Canoas. Anais... Canoas: EBRAPEM, 2012. p. 1-15.

BALL, D.L.; THAMES, M.H. e PHELPS, G. Content knowledge for teaching: what makes it special? Journal of teacher educacion, v.59, n.5, p. 389-407, 2008.

BARRETO, Fernanda; AMARAL, Fábio; BORBA, Rute. Como o raciocínio combinatório tem sido apresentado em livros didáticos de séries iniciais. Caderno de Trabalhos de Conclusão de Curso de Pedagogia, v. 2, p. 1-21, 2007.

BRASIL. Secretaria de Ensino Fundamental. Parâmetros Curriculares Nacionais. Matemática. 1aa a 4ª série. Brasília: MEC, 1997.

CAFÉ, Ângela Barcellos. Dos contadores de histórias e das histórias dos contadores. Dissertação (Mestrado em Educação) - Universidade Estadual de Campinas, Campinas, 2000.

CONTIL, Keli Cristina; MOURÃO, Gabriela Maria de Lima; BELO, Roberta A. de Castilho. Histórias e mais histórias: resolução de problemas na educação infantil. Cadernos de Pedagogia, v. 8, n. 15, p. 1-10, 2014.

CURI, Edda; PIRES, Célia Maria. A formação matemática de professores dos anos iniciais do ensino fundamental face às novas demandas. ENCONTRO NACIONAL DE EDUCAÇÃO MATEMÁTICA, 8., 2004, Recife. Anais... Recife: ENEM, 2004. p. 1$17 .$.

GAUTHIER, Clermont. Por uma teoria da pedagogia. Pesquisas contemporâneas sobre o saber docente. lju:, Editora Unijuí, 1998.

MELO, Joaline Soares Damasceno de. Matemática e literatura infantil na resolução de problemas: adição e subtração. $2^{\circ}$ CONGRESSO NACIONAL DE EDUCAÇÃ̃O, 2., 2015, Campina Grande. Anais... Campina Grande: CONEDU, 2015, 1-12. 
PERNAMBUCO. Secretaria de Educação. Parâmetros para a Educação Básica do Estado de Pernambuco: Matemática. Recife: SE, 2012

PESSOA, Cristiane. Quem dança com quem: o desenvolvimento do raciocínio combinatório do $2^{\circ}$ ano do ensino fundamental ao $3^{\circ}$ ano do ensino médio. Tese (Doutorado em Educação) - Programa de Pós-graduação em Educação da UFPE, Recife, 2009.

PESSOA, Cristiane; BORBA, Rute. Quem Dança com Quem: o desenvolvimento do raciocínio combinatório de crianças de 1a a 4a serie. Zetetike - Cempem - FE Unicamp - v17, n.31 - jan/jun - 2009.

PESSOA, Cristiane; SANTOS, Laís Thalita. Gato, Gota, Toga... A combinatória no 5ำ Ano do ensino fundamental. UNOPAR, v. 13, n. 2, p. 35-48, out 2012.

Resolução de problemas combinatórios a partir de material manipulativo e de lápis e papel: intervenções no $5^{\circ}$ ano do ensino fundamental. Revista Educação Online, n. 18, p. 1-26, jan-mai 2015.

PESSOA, Cristiane; SILVA, Monalisa. A aprendizagem da combinatória por alunos do 9ํano do ensino fundamental. RPEM, v.2, n.3, p. 1-25, jul-dez 2013.

PIRES, Célia Maria Carolino. Reflexões sobre os cursos de licenciatura em matemática. Educação Matemática em Revista, v.9, n.11, p. 44-56, 2001.

ROCHA, Cristiane de Arimatéia. Formação docente e o ensino de problemas combinatórios: diversos olhares, diferentes conhecimentos. Dissertação (Mestrado em Educação Matemática e Tecnológica) - UFPE, Recife, 2011.

RODRIGUES, Renata; SOUZA, Silvana. Literatura infantil e matemática: um diálogo lúdico e possível. CONGRESSO DE LEITURA DO BRASIL, 16., 2007, Campinas.

Anais... Campinas: COLE, 2007, p. 1-9.

RYSDYK, Márcia Regina de Azeredo. A matemática do era uma vez. Trabalho de Conclusão de Curso (Pedagogia) - Universidade Federal do Rio Grande do Sul, Porto Alegre, 2010.

SHULMAN. Conocimiento y enseñanza: fundamentos de la nueva reforma. Profesorado. Revista de currículum y formación del professorado, v. 9 n.2, p.1-30, 2005.

SILVA, Adelmo Carvalho. Literatura infantil e a formação de conceitos matemáticos em crianças pequenas. Ciências \& Cognição, v. 17, n.1. p. 21, 2012.

SILVA, Pablo Egídio Lisbôa da. Problemas combinatórios condicionais: um olhar para o livro didático do ensino médio. Dissertação (Mestrado em Educação Matemática e Tecnológica) - UFPE, Recife, 2015.

SMOLE, Kátia; DINIZ, Maria Ignez; CÂNDIDO, Patrícia. Resolução de problemas. Porto Alegre: Artmed, 2000. vol. 2.

SMOLE, Kátia Cristina Stocco et al. Era uma vez na matemática: uma conexão com a literatura infantil. 3ㄹed. São Paulo: IME-USP, 1996. 
TARDIF, Maurice. Saberes docentes e formação profissional. 9ª̣ed. Petrópolis, RJ: Vozes, 2008.

VERGNAUD, Gérard. Psicologia do desenvolvimento cognitivo e didática das matemáticas. Um exemplo: as estruturas aditivas. Análise Psicológica, v.5, n.1, p.7590, 1986.

A teoria dos campos conceptuais. In: BRUM, Jean (Org.) Didáctica das matemáticas. Lisboa: Horizontes Pedagógicos, 1996. p.280. 